\title{
Incidence of and mortality from cancer in hypertensive patients
}

\author{
D J Hole, V M Hawthorne, C G Isles, Sarah M McGhee, J W K Robertson, C R Gillis, \\ Jean A Wapshaw, A F Lever
}

West of Scotland Cancer Surveillance Unit, Ruchill Hospital, Glasgow G20 9NB

D J Hole, principal epidemiologist

C R Gillis, consultant

epidemiologist

Department of Epidemiology, University of Michigan, School of Public Health, Ann Arbor, MI 48109, USA

V M Hawthorne, emeritus professor

Dumfries and Galloway Royal Infirmary, Dumfries DG1 4AP

C G Isles, consultant physician

Glasgow Blood Pressure Clinic, Western Infirmary, Glasgow G11 6NT

Sarah M McGhee, manager Jean A Wapshaw, former manager

Management Services Division, Greater Glasgow Health Board, Glasgow G1 1PT

J W K Robertson, systems analyst

MRC Blood Pressure Unit, Western Infirmary, Glasgow G11 6NT

A F Lever, director

Correspondence to:

Professor Lever.

BMF 1993;306:609-11

TABLE I-Patient characteristics by treatment group

\begin{tabular}{lcccc}
\hline & \multicolumn{3}{c}{ Treatment group } \\
\cline { 2 - 3 } & Atenolol & Other $\beta$ blockers & Non $\beta$ blockers & All \\
\hline Men: & $(\mathrm{n}=1314)$ & $(\mathrm{n}=569)$ & $(\mathrm{n}=1271)$ & $(\mathrm{n}=3154)$ \\
Mean age (years) & 51.3 & $50 \cdot 0$ & 47.4 & 49.5 \\
$\%$ Of smokers & 53.8 & 61.9 & 58.1 & 57.0 \\
Women: & $(\mathrm{n}=1362)$ & $(\mathrm{n}=595)$ & $(\mathrm{n}=1417)$ & $(\mathrm{n}=3374)$ \\
Mean age (years) & 52.0 & $50 \cdot 1$ & 46.4 & 49.3 \\
\% Of smokers & 44.1 & 41.7 & 41.4 & 42.5 \\
\hline
\end{tabular}
seen in the Glasgow Blood Pressure Clinic between 1972 and 1990. Patients' records were linked with the registrar general's data for information on mortality and with the West of Scotland Cancer Registry for information on incident and fatal cancers. Cancers were compared in patients and controls and in patients taking atenolol, $\beta$ blockers other than atenolol, and hypotensive drugs other than $\beta$ blockers.

Subjects -6528 male and female patients providing 54355 years of follow up.

Setting-Hypertension clinic in Glasgow.

Main outcome measures-Observed numbers of cancers in clinic patients were compared with expected numbers derived from cancer rates in two control populations adjusted for age, sex, and time period of data collection.

Results-Cancer mortality was not significantly different in clinic patients as a whole and controls. Incident and fatal cancers were not significantly increased in male or female patients taking atenolol. Cancer incidence did not rise in the clinic after a large increase in prescriptions for atenolol after 1976.

Conclusion-This analysis does not suggest a link between atenolol and cancer.

\section{Introduction}

A recent Medical Research Council trial shows higher cancer mortality in elderly hypertensive men treated with atenolol. ${ }^{1}$ The excess was not present in women and the finding in men came from one of several subgroup analyses. As the authors point out, it could well be a chance finding. We compared the incidence of and mortality from cancer in patients of the Glasgow Blood Pressure Clinic taking atenolol and other hypotensive drugs and in two control populations. ${ }^{23}$ The analysis is based on record linkage of clinic patients with the West of Scotland Cancer Registry $^{4}$ and with the registrar general's data. ${ }^{2}$
Methods

Objectives-To assess incidence of and mortality from cancer in hypertensive patients taking atenolol, comparing the findings with two control populations and with hypertensive patients taking other drugs.

Design-Retrospective analysis of patients first

\section{DEFINITION OF COHORT}

The Glasgow Blood Pressure Clinic has a computer record of 7509 hypertensive patients seen since 1968 . Our study is based on 6528 men and women first registered between 1 January 1972 and 31 December 1990, providing 54355 patient years of follow up.

\section{CANCER MORTALITY}

When patients register with the clinic a copy of their record is flagged by the registrar to ensure that we know of deaths and their certified cause. An earlier test showed that flagging is reliable. ${ }^{2}$

\section{INCIDENT CANCERS}

The West of Scotland Cancer Registry holds information on incident as well as fatal cancers in the area. ${ }^{4}$ To identify clinic patients developing cancer, all patients seen between 1972 and 1990 were linked by computer with the registry with a method described previously.' Validation before linking showed that $92 \%$ of fatal cancers known to the clinic were also known to the registry. Also, $94 \%$ of deaths from cancers known to the registry were known to the clinic. Linking the clinic and registry identified 436 clinic patients with cancer diagnosed between 1972 and 1990 ; in 50, cancer was diagnosed before treatment for raised blood pressure began and these patients are excluded. Thus, our analysis is based on 386 incident cases all diagnosed after the introduction of treatment.

\section{TREATMENT}

Three mutually exclusive groups were defined (tables I and II). An atenolol group of 2676 patients given the drug irrespective of whether they also received other hypotensive drugs provided 16592 patient years of exposure to atenolol (table II). Exposure to a drug was taken from the date of its first prescription to date of death or to 31 December 1990, whichever came first. The other $\beta$ blocker group comprised 1164 patients receiving a $\beta$ blocker other than atenolol with or without hypotensive drugs of other types. A group not given $\beta$ blockers included the remaining 2688 patients, none of whom at any time received a $\beta$ blocker of any sort, including atenolol.

\section{STATISTICS}

Comparison of cancer mortality and incidence was based on the ratio of observed and expected cancers. "Observed" cancers were those seen in clinic patients. Two sets of "expected" numbers were derived, the first from cancer rates in the general population of the west of Scotland (first control group) standardised for age, sex, and time period of observation. Standardisation of time was necessary because cancer incidence is rising slowly in the west of Scotland and because prescribing atenolol increased greatly during the period of study (fig 1). The second set of expected values also included 

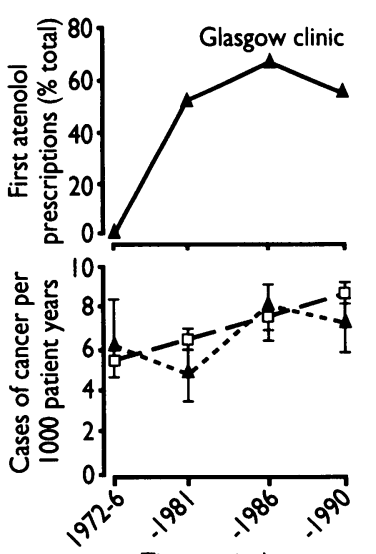

Time period

FIG 1 -First prescriptions of atenolol in clinic as percentage of all first prescriptions (- - ) and cancer incidence in clinic patients $(\cdots \Lambda)$ and in west of Scotland controls (- -$)$. The rise of cancer $(-\square-)$. The rise of cancer incidence in controls is partly increasing average age of clinic increasing average age of clinic patients with time - a cohor effect. Because controls are matched with patients for age, mean age of controls and hence their apparent cancer incidence increases with time an adjustment for smoking habit derived from data in our second control group-the Renfrew-Paisley study. ${ }^{6}$ This general population survey was of 15411 men and women screened between 1972 and 1976 and providing 231888 subject years of follow up to 31 December 1990.

Expected numbers were calculated for each group standardised for age, sex, and time period. Observed numbers were treated as data from a Poisson distribution with mean equal to the number expected. Probability values were derived from the Poisson distribution and were two tailed. No adjustment was made for multiple tests of significance. Standardisation for age, sex, and smoking habit was needed because patients in the atenolol group were slightly older, less commonly smokers, and more commonly male than patients in other treatment groups (table I). An earlier study had shown that patients at the Glasgow clinic did not contain a higher proportion of smokers than did Renfrew-Paisley controls. ${ }^{2}$

\section{Results}

Analysis in 1983 had shown no excess of cancer deaths in Glasgow clinic patients compared with Renfrew-Paisley controls. ${ }^{2}$ Because prescriptions for atenolol have increased since 1983 , we repeated the analysis, including data up to December 1990. As

TABLE II-Cancer deaths by treatment group

\begin{tabular}{|c|c|c|c|c|c|}
\hline & \multirow[b]{2}{*}{ No of patient } & \multirow[b]{2}{*}{$\begin{array}{c}\text { No of patient } \\
\text { years }\end{array}$} & \multicolumn{3}{|c|}{ No of cancer deaths } \\
\hline & & & Observed & Expected & $\begin{array}{l}\mathrm{O} / \mathrm{E}(95 \% \text { confidence } \\
\text { interval) }\end{array}$ \\
\hline All patients & 6528 & 54355 & 246 & $\begin{array}{l}245 \cdot 5^{\star} \\
250 \cdot 1 \dagger\end{array}$ & $\begin{array}{l}1.00(0.88 \text { to } 1.13) \\
0.98(0.86 \text { to } 1.11)\end{array}$ \\
\hline \multicolumn{6}{|l|}{ Treatment groups: } \\
\hline Atenolol & 2676 & 16592 & 74 & $\begin{array}{l}78 \cdot 9^{\star} \\
79 \cdot 6 \dagger\end{array}$ & $\begin{array}{l}0.94(0.74 \text { to } 1.18) \\
0.93(0.73 \text { to } 1.17)\end{array}$ \\
\hline Pure & 1691 & 9198 & 38 & $\begin{array}{l}39 \cdot 3^{\star} \\
39 \cdot 8 \dagger\end{array}$ & $\begin{array}{l}0.97(0.68 \text { to } 1.33) \\
0.95(0.68 \text { to } 1.31)\end{array}$ \\
\hline Mixed & 985 & 7394 & 36 & $\begin{array}{l}39 \cdot 6^{\star} \\
39 \cdot 8 \dagger\end{array}$ & $\begin{array}{l}0.91(0.64 \text { to } 1.26) \\
0.90(0.63 \text { to } 1.25)\end{array}$ \\
\hline Other $\beta$ blockers & 1164 & 12061 & 65 & $\begin{array}{l}55 \cdot 4^{\star} \\
56 \cdot 6 \dagger\end{array}$ & $\begin{array}{l}1.17(0.91 \text { to } 1.50) \\
1.15(0.89 \text { to } 1.46)\end{array}$ \\
\hline Non $\beta$ blockers & 2688 & 25703 & 107 & $\begin{array}{l}111 \cdot 2^{\star} \\
114 \cdot 0 \dagger\end{array}$ & $\begin{array}{l}0.96(0.78 \text { to } 1.15) \\
0.94(0.76 \text { to } 1.12)\end{array}$ \\
\hline $\begin{array}{l}\text { Smokers: } \\
\quad \text { Men taking atenolol }\end{array}$ & 707 & 4193 & 25 & $32 \cdot 5$ & $0.77(0.50$ to 1.14$)$ \\
\hline
\end{tabular}

*Based on cancer mortality in the west of Scotland population, adjusting for age, sex, and period of follow up. †Based on additional data from the Renfrew/Paisley cohort study to include adjustment for smoking status.

TABLE III-Incident cancers by treatment group

\begin{tabular}{|c|c|c|c|c|c|}
\hline & \multirow[b]{2}{*}{ No of patients } & \multirow[b]{2}{*}{$\begin{array}{l}\text { No of patient } \\
\text { years }\end{array}$} & \multicolumn{3}{|c|}{ No of incident cancers } \\
\hline & & & Observed & Expected & $\begin{array}{c}\mathrm{O} / \mathrm{E}(95 \% \text { confidence } \\
\text { interval })\end{array}$ \\
\hline All patients & 6528 & 54355 & 386 & $\begin{array}{l}421 \cdot 1 \dagger \\
426 \cdot 9 \ddagger\end{array}$ & $\begin{array}{l}0.92(0.82 \text { to } 1.01) \\
0.90(0.81 \text { to } 1.00)\end{array}$ \\
\hline \multicolumn{6}{|l|}{ Treatment group: } \\
\hline Atenolols & 2676 & 16592 & 136 & $\begin{array}{l}138 \cdot 7 \dagger \\
139 \cdot 5 \ddagger\end{array}$ & $\begin{array}{l}0.98(0.81 \text { to } 1.15) \\
0.98(0.81 \text { to } 1.14)\end{array}$ \\
\hline Pure & 1691 & 9198 & 76 & $\begin{array}{l}69 \cdot 8 \dagger \\
70 \cdot 4 \ddagger\end{array}$ & $\begin{array}{l}1.09(0.85 \text { to } 1.32) \\
1.08(0.85 \text { to } 1.31)\end{array}$ \\
\hline Mixed & 985 & 7394 & 60 & $\begin{array}{l}68 \cdot 9 \dagger \\
69 \cdot 0 \ddagger\end{array}$ & $\begin{array}{l}0.87(0.63 \text { to } 1.11) \\
0.87(0.63 \text { to } 1.11)\end{array}$ \\
\hline Other $\beta$ blockers & 1164 & 12061 & 90 & $\begin{array}{l}94 \cdot 8 \dagger \\
96 \cdot 2 \ddagger\end{array}$ & $\begin{array}{l}0.95(0.75 \text { to } 1.15) \\
0.94(0.74 \text { to } 1.14)\end{array}$ \\
\hline Non $\beta$ blockers & 2688 & 25703 & 160 & $\begin{array}{l}187 \cdot 6 \dagger \\
191 \cdot 1 \neq\end{array}$ & $\begin{array}{l}0.85(0.71 \text { to } 0.99)^{\star} \\
0.83(0.69 \text { to } 0.97)^{\star}\end{array}$ \\
\hline
\end{tabular}

${ }^{\star} \mathrm{p}<0.05$.

AA second series of comparisons was made of the risk of cancer in the atenolol group with that in the other $\beta$ blocker group, adjusting for age, sex, smoking status, and time period (relative hazard ratio $1 \cdot 11 ; 95 \%$ confidence interval group, adjusting for age, sex, smoking status, and time period (rel
0.74 to 1.65$)$ and with the non $\beta$ blocker group $(1.22 ; 0.90$ to 1.67$)$.

†Based on cancer incidence in the West of Scotland Cancer Registry population, adjusting for age, sex, and period of follow up.

$\ddagger$ Based on additional data from the Renfrew/Paisley cohort study to include adjustment for smoking status.

before, cancer was not significantly more common in clinic patients than in controls though, as expected in a hypertension clinic, cardiovascular causes of death showed a greater than twofold excess in men, and slightly less in women (fig 2).

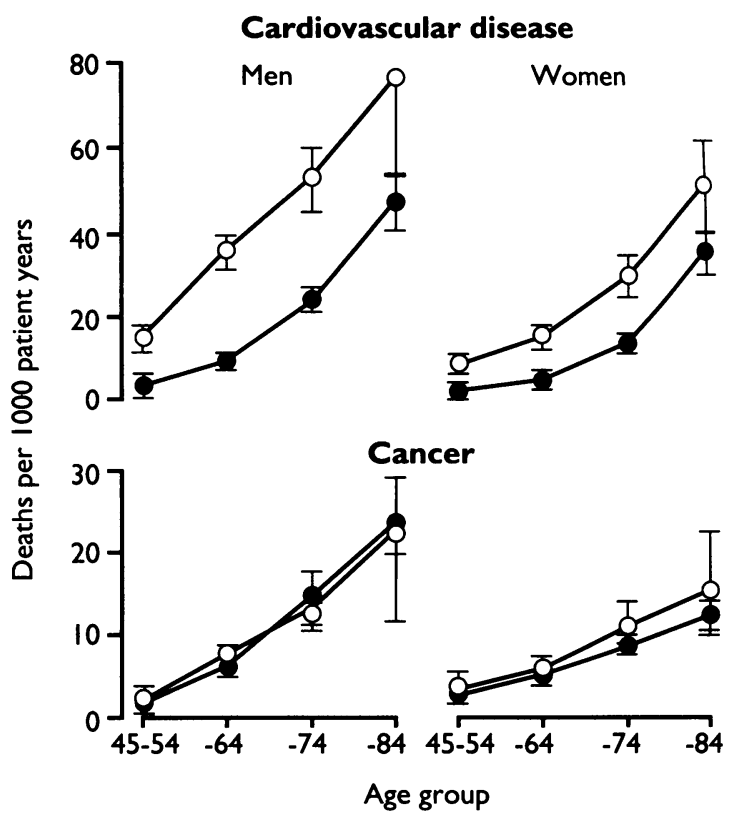

FIG 2-Age specific mortality for all cardiovascular disease (top) and for cancer (bottom) in men and women attending Glasgow Blood Pressure Clinic (-O) and in Renfrew-Paisley controls (- - ). Bars indicate $95 \%$ confidence intervals

Cancer mortality was not higher in patients receiving atenolol than in controls (table II), nor was it higher in the atenolol group than in the other $\beta$ blocker group, adjusted for age, sex, smoking status, and time period (relative hazard ratio $0.71 ; 95 \%$ confidence interval 0.45 to 1.11$)$ and with the non $\beta$ blocker group ( 0.88 ; 0.61 to $1 \cdot 28$ ). Comparison with and without adjustment for smoking gave similarly negative results. Cancer mortality was not higher in the subgroup of interest in the MRC trial,' male smokers taking atenolol.

Cancer incidence was not increased in patients taking atenolol as compared with controls and with patients taking other forms of treatment (table III). Confidence intervals in this analysis make unlikely a risk of cancer greater than $15 \%$ in patients taking atenolol. Subgroups taking atenolol alone, atenolol with other drugs, and $\beta$ blockers other than atenolol had risk ratios not significantly different from 1.0 (table III). The group taking hypotensive drugs other than $\beta$ blockers had a significantly lower risk than the general population.

Smoking and differences in men and women-Apart from one subgroup, no significant excess of incident cancer was seen in the three treatment groups, in men and women, and in smokers and non-smokers (table IV). The exception, a significant excess of $58 \%$, was in male non-smokers taking atenolol. However, this was one of 24 analyses (table IV) and the excess, of 13 patients only, was balanced by a deficiency of 12 cancers in male smokers taking atenolol. Combining smoking and non-smoking men taking atenolol gave a risk ratio of 1.01

Age had no significant influence on the relation of cancer incidence and drug treatment, apart from a $76 \%$ excess of cancers in the oldest age group taking $\beta$ blockers other than atenolol (table V). This group contained the smallest number of cases (19) and the excess was based on eight patients only.

Sites of cancer-Kidney cancer was the only type to be significantly increased (table VI). As some kidney cancers cause hypertension ${ }^{78}$ an increased frequency of kidney cancer is to be expected in a hypertension 
TABLE IV-Cancer incidence by sex and smoking status. Values are observed:expected ratio (number of cancers observed/number expected)

\begin{tabular}{|c|c|c|c|c|}
\hline & \multicolumn{3}{|c|}{ Treatment group } & \multirow[b]{2}{*}{ All } \\
\hline & Atenolol & Other $\beta$ blockers & Non $\beta$ blockers & \\
\hline Men & $1 \cdot 01(75 / 74 \cdot 3)$ & $0.94(46 / 48.9)$ & $0.80(77 / 96 \cdot 4)$ & $0.90(198 / 219 \cdot 6)$ \\
\hline Non-smokers & $1.58(35 / 22 \cdot 2)^{\star}$ & $0.96(12 / 12.5)$ & $0.62(16 / 25.9)$ & $1.04(63 / 60.6)$ \\
\hline Smokers & $0.77(40 / 52 \cdot 1)$ & $0.93(34 / 36.4)$ & $0.87(61 / 70.5)$ & $0.85(135 / 159 \cdot 0)$ \\
\hline Women & $0.94(61 / 65 \cdot 2)$ & $0.93(44 / 47.5)$ & $0.88(83 / 94 \cdot 7)$ & $0.91(188 / 207.3)$ \\
\hline Non-smokers & $0.91(32 / 35.0)$ & $1.02(28 / 27.5)$ & $0.83(43 / 52 \cdot 1)$ & $0.90(103 / 114.5)$ \\
\hline Smokers & $0.96(29 / 30 \cdot 2)$ & $0.80(16 / 20.0)$ & $0.92(40 / 42 \cdot 6)$ & $0.91(85 / 92.8)$ \\
\hline
\end{tabular}

Expected values were adjusted for age, period of follow up, and smoking status; because of the adjustment for smoking, risk ratios do not differ in smokers and non-smokers. ${ }^{\star} \mathrm{p}<0.05$.

TABLE V-Incident cancers: influence of age and treatment group. Values are observed:expected ratio (number of cancers observed/number expected)

\begin{tabular}{|c|c|c|c|c|}
\hline \multirow[b]{2}{*}{ Age group } & \multicolumn{3}{|c|}{ Treatment group } & \multirow[b]{2}{*}{ All } \\
\hline & Atenolol & Other $\beta$ blockers & Non $\beta$ blockers & \\
\hline $\begin{array}{l}\text { Under } 55(n=4048) \\
55-64 \text { years }(n=1832) \\
65 \text { and over }(n=648)\end{array}$ & $\begin{array}{l}1 \cdot 12(47 / 42 \cdot 1) \\
1 \cdot 00(67 / 67 \cdot 0) \\
0 \cdot 74(22 / 29 \cdot 6)\end{array}$ & $\begin{array}{l}0.79(35 / 44 \cdot 3) \\
0.91(36 / 39 \cdot 7) \\
1.76(19 / 10 \cdot 8)^{\star}\end{array}$ & $\begin{array}{l}0.85(69 / 81 \cdot 2) \\
0.91(65 / 71 \cdot 8) \\
0 \cdot 75(26 / 34 \cdot 7)\end{array}$ & $\begin{array}{l}0.90(151 / 167 \cdot 6) \\
0.94(168 / 178 \cdot 4) \\
0.89(67 / 75 \cdot 0)\end{array}$ \\
\hline
\end{tabular}

Expected values were adjusted for sex, period of follow up, and smoking status. ${ }^{\star} \mathrm{p}<0.05$.

TABLE VI-Incident cancers by anatomical site

\begin{tabular}{|c|c|c|c|c|c|c|}
\hline \multirow[b]{2}{*}{ Site or type } & \multicolumn{3}{|c|}{ All patients } & \multicolumn{3}{|c|}{ Patients taking atenolol } \\
\hline & Observed & Expected & $\mathrm{O} / \mathrm{E}$ & Observed & Expected & $\mathrm{O} / \mathrm{E}$ \\
\hline Lung & 92 & $97 \cdot 2$ & 0.95 & 24 & 32.5 & 0.74 \\
\hline Breast & 39 & $47 \cdot 2$ & 0.83 & 14 & $14 \cdot 9$ & 0.94 \\
\hline Skin & 39 & 40.8 & 0.96 & 13 & $14 \cdot 0$ & 0.93 \\
\hline Colon & 18 & $29 \cdot 0$ & 0.62 & 7 & $9 \cdot 1$ & 0.77 \\
\hline Stomach & 21 & $21 \cdot 2$ & 0.99 & 7 & 6.5 & 1.08 \\
\hline Bladder & 22 & 20.7 & 1.06 & 8 & $7 \cdot 1$ & 1.13 \\
\hline Rectum & 13 & $15 \cdot 2$ & 0.86 & 6 & $4 \cdot 8$ & 1.25 \\
\hline Prostate & 7 & $14 \cdot 2$ & 0.49 & 5 & $5 \cdot 0$ & 1.00 \\
\hline Pancreas & 12 & 10.5 & $1 \cdot 14$ & 4 & $3 \cdot 3$ & $1 \cdot 21$ \\
\hline Oesophagus & 8 & $10 \cdot 6$ & 0.75 & 1 & $3 \cdot 6$ & 0.28 \\
\hline Ovary & 13 & $9 \cdot 4$ & 1.38 & 6 & $3 \cdot 0$ & $2 \cdot 00$ \\
\hline \multicolumn{7}{|l|}{ Non-Hodgkin's } \\
\hline lymphoma & 8 & $9 \cdot 1$ & 0.88 & 3 & $3 \cdot 1$ & 0.97 \\
\hline Cervix & 4 & $7 \cdot 7$ & 0.52 & 1 & $2 \cdot 3$ & 0.43 \\
\hline "Secondaries" & 10 & $7 \cdot 9$ & 1.27 & 4 & $2 \cdot 6$ & 1.54 \\
\hline Kidney & 14 & $7 \cdot 5$ & $1.87^{\star}$ & 5 & $2 \cdot 6$ & 1.92 \\
\hline Leukaemia & 6 & $6 \cdot 4$ & 0.94 & 1 & $2 \cdot 0$ & 0.50 \\
\hline Melanoma & 4 & $6 \cdot 0$ & $0 \cdot 67$ & 3 & $2 \cdot 1$ & 1.43 \\
\hline Myeloma & 4 & $4 \cdot 1$ & 0.98 & 2 & 1.3 & 1.54 \\
\hline Total & 386 & $421 \cdot 1$ & 0.92 & 136 & $138 \cdot 7$ & 0.98 \\
\hline
\end{tabular}

Expected values were based on cancer incidence data from West of Scotland Cancer Registry area and adjusted for age, sex, and period of follow up but not for smoking status.

${ }^{\star} \mathrm{p}<0.05$ for all patients. hazards model also showed no reduction of survival time in a comparison of the period when atenolol was prescribed (1977-90) with the period in which it was not prescribed (1972-6).

\section{Discussion}

The MRC study showed higher cancer mortality in men randomised to atenolol. ${ }^{\prime} \mathrm{A}$ report by Coope and Warrender also suggests an excess of cancer in patients taking the drug. ${ }^{9}$ In contrast with these, we found no excess of incident or fatal cancer in male or female hypertensive patients taking atenolol; similarly, Fletcher and colleagues found no difference of relative risk for cancer in patients taking atenolol, other $\beta$ blockers, methyldopa, or diuretics. ${ }^{10}$

Patients in the MRC trial were over 65 years of age, but only a small proportion of cancer deaths in our study were in patients in this age group. In these, there was no excess in those taking atenolol, but the number of cancers was small (22). The MRC trial was a randomised comparison of two forms of active treatment and placebo. Our study did not have these important advantages. Although lack of randomisation may introduce bias, a bias relating to cancer is unlikely to have influenced either referral of patients to our clinic or choice of treatment within the clinic. Patients known to have cancer before treatment were excluded. Ascertainment bias might lead to earlier detection of cancer in regularly supervised patients, but against this as a factor in our case the survival times in cancer patients and the frequency of incident and fatal cancers were not different in clinic patients and controls (figs 1 and 2 ; table II).

The number of events in a study determines its statistical power. In our analysis and in that of Fletcher and colleagues, ${ }^{10}$ the number of events (incident and fatal cancers) exceeded that in the MRC trial. We have the additional advantage of data on incidence, which is important because incidence rises before mortality when a newly introduced drug does cause cancer. In the MRC trial cancer mortality was assessed during prescription of atenolol for five to six years. Our analysis covers a 19 year period and includes some patients who took atenolol for over 10 years. The incidence of cancer did not rise during this time (fig 2).

The authors of the MRC trial suspected that the significant excess of cancer seen in men taking atenolol was a chance observation. Our findings and those of Fletcher $e t a l^{10}$ strongly support this.

clinic. Lung cancer, which contributed most to the excess seen in the MRC trial, ${ }^{1}$ was not more common in clinic patients as a whole or in the subgroup taking atenolol (table VI).

Timing of cancer in relation to timing of atenolol prescription-First prescriptions for atenolol in the clinic were in 1976 . By $1980,77 \%$ of new prescriptions were for the drug (fig 1). Cancer incidence showed no increase in clinic patients after 1976 and no increase relative to controls at any time (fig 1 ).

Survival time-Theoretically, a drug may increase cancer incidence either by causing new cancers or by accelerating the growth of existing cancers. The second effect would appear earlier than the first and would be manifest by a reduction of survival time - the interval between diagnosis of cancer (incidence date) and death. Using Cox's proportional hazards model and adjusting for age, sex, and site of cancer, we found that survival time in the atenolol and $\beta$ blocker groups was no different from that in the group not taking $\beta$ blockers (risk ratios 1.02 and 0.88 , respectively). The
1 Medical Research Council Working Party. Medical Research Council trial of treatment of hypertension in older adults: principal results. BMF 1992;304: 405-12.

2 Isles CG, Walker LM, Beevers DG, Brown I, Cameron HL, Clarke J, et al. Mortality in patients of the Glasgow Blood Pressure Clinic. $f$ Hypertensio 1986;4:141-56.

3 Hawthorne VM, Greaves DA, Beevers DG. Blood pressure in a Scottish town. $B M$ 1974; iii:600-3 $^{2}$

4 Gillis CR, Hole DJ, Lamont D, Boyle P, Graham A. Cancer incidence in the West of Scotland. In: Muir C, Waterhouse J, Mack T, Powell J, Whelan S eds. Cancer incidence in five continents. Vol V. Lyons: International Association for Research on Cancer, 1987:704-7.

5 Hole DJ, Clarke DJ, Hawthorne VM, Murdoch RM. Cohorts following using computer linkage with routinely collected data. 7 Chron Dis 1981;34:291-7.

6 Gillis CR, Hole DK, Hawthome VM. Cigarette smoking and male lung cancer in an area of very high incidence. II. Report of a general population cohort study in the West of Scotland. 7 Epidemiol Community Health 1988;42:44-8

7 Ram MD, Chisholm GD. Hypertension due to hypernephroma. BMI 1969;iv:87-8.

8 Neilsen HO. Arterial hypertension due to a renin-producing renal carcinoma. Scand I Nephrol 1973;9:293-6.

9 Coope J, Warrender TS. Randomised trial of treatment of hypertension in

10 Fletcher AE, Beevers DG, Bulpitt CJ, Coles CJ, Dollery CT, Ledingham JG et al. Cancer mortality in atenolol treatment: a report from the Departmen of Health Hypertension Care Computing Project (DHCCP). BMJ 1993;306:622-3.

(Accepted 27 November 1992) elderly patients in primary care. $B M \mathcal{F} 1986 ; 293: 1145-51$. 